\title{
Effect of Acceleration and Deceleration Power Exercises on improving Offensive Move without a Ball in Juniors' Basketball matches
}

\section{Sara Helmy Moselhy}

Lecturer at Sports Games Training Department, Faculty of Physical Education for Girls, Helwan University, Cairo, Egypt.

\section{Abstract:}

A distinguished basketball team is a team whose members know how to use their feet to the best of their ability and move strategically on the court without a ball in matches; they know how to sprint suddenly and quickly, change direction without warning, stop abruptly without slowing down gradually, change their pace when necessary, and jump high at the exact moment to get rid of the opponent. This study aims at determining effect of acceleration and deceleration power exercises on improving acceleration and deceleration level and offensive move without a ball of female juniors' basketball matches, through using the experimental approach for one group $(n=$ 20) of female basketball junior players under 10 years old at Wadi Degla Club-Maadi, Egypt.

The training program for acceleration and deceleration power exercises of the experimental group was applied for (16) weeks, with (3) units per week in the special preparation period, the pre-match preparation period and the match period of season 2020/2021. The tests used for pre, inter and post measurements were: a $3 \times 3$ match to analyze the offensive move without a ball for juniors using Utilius ${ }^{\circledR}$ Vs Advanced version (4.5.8), a 10-m sprint test measuring acceleration and a 5-0-5 sprint test to measure deceleration. The most important results were the presence of statistically significant differences between pre, inter, and post measurements in improving the level of acceleration and deceleration of basketball female juniors in favor of the post measurement. Moreover, there were statistically significant differences between pre, inter, and post measurements in improving the level of offensive move without a ball for female juniors' basketball matches in favor of the post measurement. Subsequently, it can be concluded that acceleration and deceleration power exercises have a positive effect on improving the level of offensive move without a ball for female juniors' basketball matches.

Key Words: Acceleration and Deceleration power, Offensive move, Plyometric exercises, $3 x 3$

\section{Introduction:} matches, juniors training.

Basketball $3 \times 3$ is a game of smart moves in offense and defense, but the task of the offensive move requires a higher ability of smart moves than the defense because of the need to find continuous solutions to score within 12 seconds in a half court with three defenders (Conte et al., 2019; McGown et al., 2020; Sicinski, 2008), while defending players' movements are mostly subject to the actions of the offensive team (Sansone et al., 2020). The offensive move in basketball is divided into an offensive move with a ball and an offensive move without a ball (Taskin, 2020).

As a matter of fact, when it comes to the efficiency and effectiveness of offensive move in basketball games, it is just as important - if not more - to move well without a ball than it is to move with one (Sicinski, 2008), for players spend four-fifths of the time without a ball. What the player does at this time is directly related to the success of the attack and of the team (Guide to Coaching Basketball, 2012).

Knowing how to execute an offensive move effectively on basketball court without a ball is an essential aspect of the game and critical to opening up distinct and large spaces for the offensive player to escape from the defender, receive the ball, and scoring. However, there are 
few players who are proficient in this skill, especially against strong defensive teams, as many junior coaches pay great attention to teaching youth offensive skills with a ball and excel in training programs for developing this technique and neglect the value of the offensive move skill without a ball and its impact on the result of the matches, and what are the physical requirements necessary to master them, so they limit their physical requirements to the maximum speed (Emory \& Henry, 2021; Johnston, 2016; Sicinski, 2008).

They think that a faster athlete has a distinct competitive advantage over slower competitors, but speed in most team-based sports such as basketball is characterized by sudden changes in pace, unexpected stops, jumps, turns and changes in multiple directions (Dawes \& Lentz, 2012; Kumar, 2014).

Training players to be faster regardless of the nature of the game and its requirements leads them to two results: first, they are unable to change the course of sprinting to another direction in response to the requirements of the game; current studies revealed that faster players in different sports are generally less efficient in changing direction than their slower peers (Freitas et al., 2019; Loturco et al., 2019; Loturco et al., 2018; Pereira et al., 2018) .The second, if players try to suddenly change the course of sprinting to another direction with this pace, they will expose themselves to the inevitable injury, as indicated by Pasanen et al. (2017) study, stating that the most common injuries for basketball players are injuries to the lower limb related to joints and ligaments, most were due to sprained ankles (48\%), and knees (15\%).

As aforementioned, and by watching $3 \times 3$ matches for juniors during the first round of the league for the season 2019/2020, the researcher found that the players preferred to perform 1vs1 offense as they noticed that their colleagues couldn't outmaneuver the defenders watching them and receive and pass the ball, and if the players pass to their teammates, the ball is cut off before reaching them. This is a result of the offense players' lack of good movement on court, especially without the ball, and their inability to optimally use the offensive footwork at the speed that helps them escape from the defender in an effective manner that allows them to receive the pass. American Sport Education Program (2007) states that one of the first skills must be taught to junior players is how to move on the court, if players can move correctly on court at the appropriate speed, this will help them implement the requirements of the matches, escape the defenders, receive the ball correctly and participate in the attack process effectively without causing injuries. The offensive move skill without a ball is a complex skill that includes many moves such as (Quick Start, Change of Pace, Change of Direction, Jump Stop, stride stop, Jump and Land, Pivot and Turn Forward and Backward) (Arumugam et al., 2020). These moves require a variety of adjustments in foot position, stride rate, and stride frequency to be effective and the attacker can escape from the defender watching her (Dawes \& Lentz, 2012).

According to these moves, players should have the ability to hastily generate explosive muscular powers to pace up change of direction, slow down, jump stop, and re-accelerate in a relatively short distance, and implement successive changes of direction to deal better with the demands of the matches. These juniors should be trained to acquire the ability to decelerate and accelerate over short distances in multiple directions rather than dedicate most of their training time to developing a maximum line speed inconsistent with the nature of $3 \times 3$ basketball (Dawes \& Lentz, 2012; Loturco et al., 2019).

This is what Herrán et al. (2017) pointed in the recommendations of their study, that basketball coaches must take into account the acquisition and training of players to accelerate and decelerate being a physical requirement necessary to suit the movements in $3 \times 3$ basketball matches. 
Hence, the researcher is set to design a training program to develop the ability to accelerate and decelerate, to be implemented on junior players during the special preparation period, prematches preparation, and the match period aiming at improving the offensive movement without a ball in basketball matches.

This study aims at determining effect of acceleration and deceleration power exercises on improving acceleration and deceleration level and offensive move without a ball of female juniors' basketball matches.

\section{Hypothesis:}

(1) There are statistically significant differences between pre, inter, and post measurements on improving acceleration and deceleration level of female junior basketball players (experimental group) in favor of post measurement.

(2) There are statistically significant differences between pre, inter, and post measurements on improving offensive move without a ball level of female juniors' basketball matches (experimental group) in favor of post measurement.

\section{Methods:}

\subsection{Approach}

Experimental method was used through using the experimental design for one group through pre, inter, and post measurement.

\subsection{Sample}

A deliberate sample was chosen from female junior players of Wadi Degla Club, Maadi branch under 10-year-old, who are registered with the Egyptian Basketball Federation for the season 2020/2021. The sample consisted of (25) female players and were randomly distributed (20) for the experimental group (Mean: \pm SD: age: $9.32 \pm 0.48$ years; training age: $1.69 \pm 0.45$ years; weight: $32.25 \pm 3.14 \mathrm{~kg}$; height: $145.20 \pm 7.26 \mathrm{~cm}$ ) and (5) for the pilot study.

Note: Sample normality distribution was confirmed under the normal curve of height, weight, age, and training age variables, thus the skewness coefficient values were between (- 1.66, +0.26 ); also, physical variables affecting offensive move without a ball skill consistent with legs coordination and arms power "right-left", legs power, acceleration and deceleration, agility, legs response movement time and dynamic balance of the legs "right-left" (Moawad, 2003; Zedan, 2014), thus the skewness coefficient values were between $(-1.05,+0.46)$; the technical variable of the offensive move without a ball in $3 \mathrm{X} 3$ matches which were divided in terms of " effective and ineffective" movement, so skewness coefficient was between $(+0.87,+1.47)$; it is clear then that skewness coefficient is limited between $( \pm 3)$, indicating the normality distribution of the sample members in all study variables.

\subsection{Procedures}

- The following physical tests were used to measure physical variables affecting the offensive move skill without a ball: (Numbered Circles Test) to measure the legs coordination, (Illinois Agility Test) to measure agility, (a 10-meter Sprint Test) to measure acceleration, (5 - 0 - 5 meter Sprinting Test) to measure deceleration, (Star Excursion Balance Test) to measure dynamic balance, (Nelson Test for response movement time) to measure the legs response movement time, (One-handed Medicine Ball Push "2kgs") to measure the arms power, (Standing Board Jump Test) to measure legs power. The physical tests are described briefly as follows:

\section{Numbered Circles Test}

The player stands inside circle No. (1), upon the start signal she jumps with both feet to circle No. (2) and then to circle No. (3) and so on, until reaching the circle No. (8). This is done 
at full speed, and the time taken by the player to move across (8) circles is recorded (Hassanein, 1987), as in Figure 1.

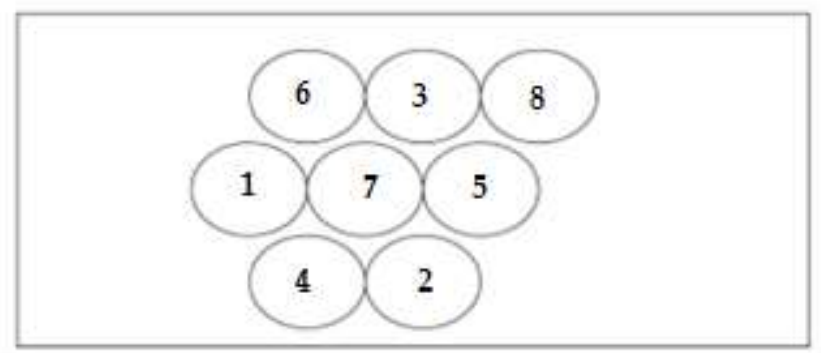

Figure 1. Numbered Circles Test

\section{Illinois Agility Test}

The player stands behind the start line and once she hears the launch signal, she runs at a maximum speed following the black arrow, as in the illustration, from start to end points, time is recorded to the closest 1/10 second (Gambetta, 2007), as in Figure 2.

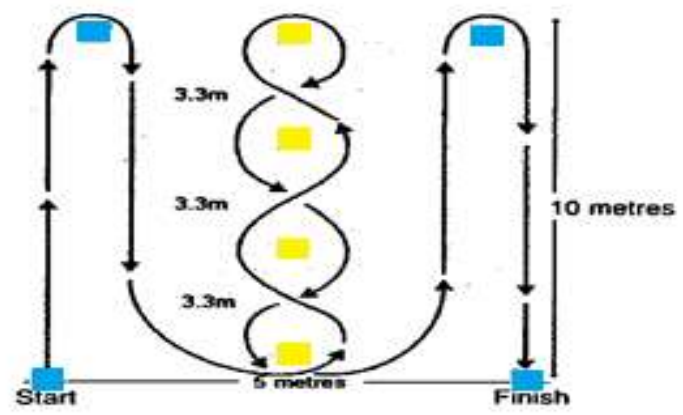

Figure 2. Illinois Agility Test

\section{0-meter Sprint Test}

The player stands behind the start line, once she hears the whistle she runs at a maximum speed until the end line, time is recorded to the closest 1/10 second (Gambetta, 2007), as in Figure 3.

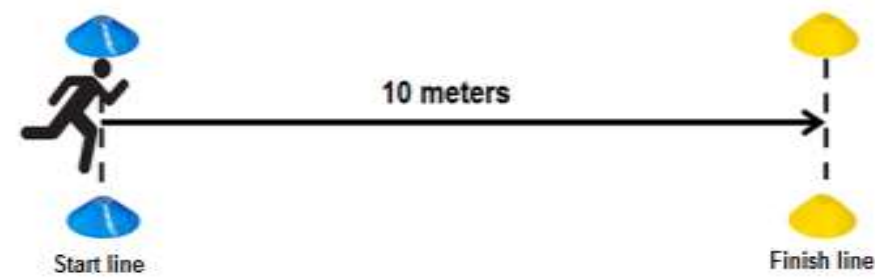

Figure 3. 10-meter Sprint Test

\section{5-0-5 meter Sprint Test}

The player stands behind the start line and once she hears the whistle she runs at a maximum speed until the third cone "turning line", once she is there, the player circles it and returns at a maximum speed. The time is recorder for the player starting the second cone passing the third cone and then returning to the second cone to the closest 1/10 second (Clark, et al. 2010), as in Figure 4. 


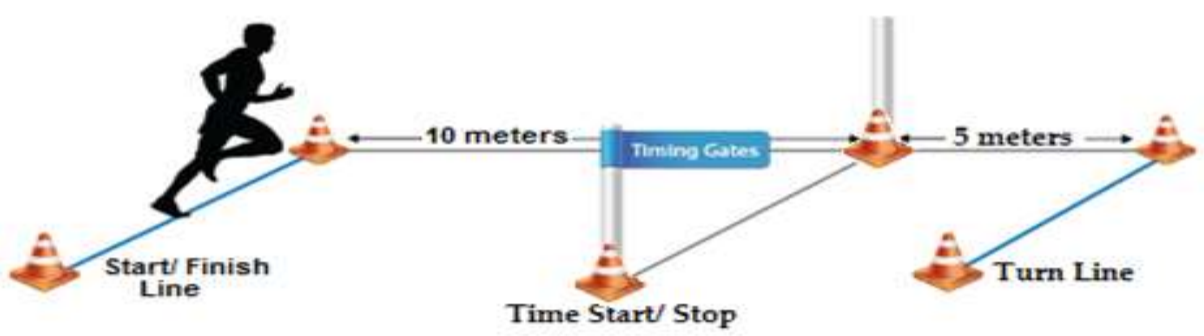

Figure 4. 5-0-5 meter Sprint Test

\section{Star Excursion Balance Test}

The player stands with her right foot in the midpoint of the net (i.e. the meeting point of all 8 lines), and extends the instep of the left leg to touch the farthest distance she can reach on line No. (1) while the referee places a mark for her and then returns to standing with both feet in the middle, then repeats the same thing in line No. (2) and so on up to line No. (8), while keeping the direction of the body forward as it was at the beginning. The distance is measured to the nearest centimeter from the midpoint of all lines and the same is repeated with the other foot; The following equation is used to calculate the degree of equilibrium in dynamic balance:

The average distance of the (8) lines of the right foot / leg length $\times 100=$ balance degree. The same equation is used to calculate balance degree of the left foot (Haff \& Triplett, 2016), as in Figure 5.

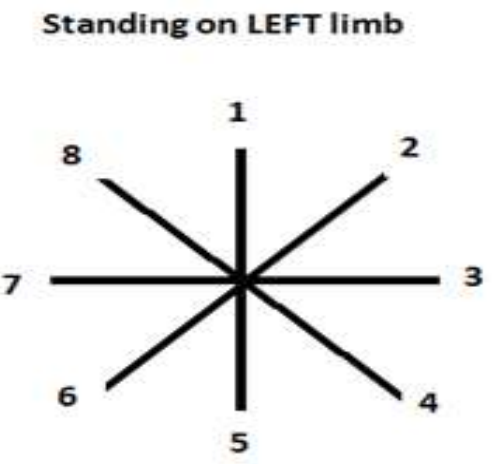

\section{Standing on RIGHT limb}

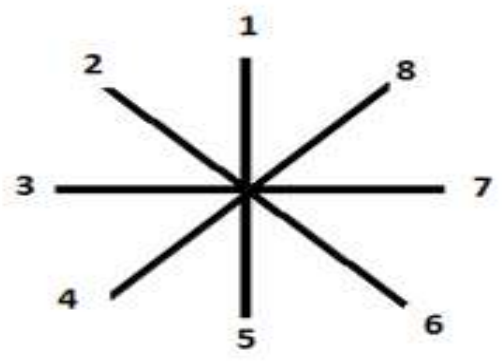

Figure 5. Star Excursion Balance Test

\section{Nelson Test for response movement time}

The player stands at the beginning of the midline in a high standby mode opposite to the referee who holds the stopwatch, the referee signals to the right or left then starts the watch, the player runs towards the appointed line and once she crosses it the referee stops the watch. If the player ran in the wrong direction, the watch does not stop until she crosses the appointed line. (6) attempts are counted for the player, between each attempt (20) seconds rest, hence (3) the right side and (3) the left one, time is calculated for each attempt, and the player's score is the average number of the (6) attempts (Majeed, 1998), as in Figure 6. 


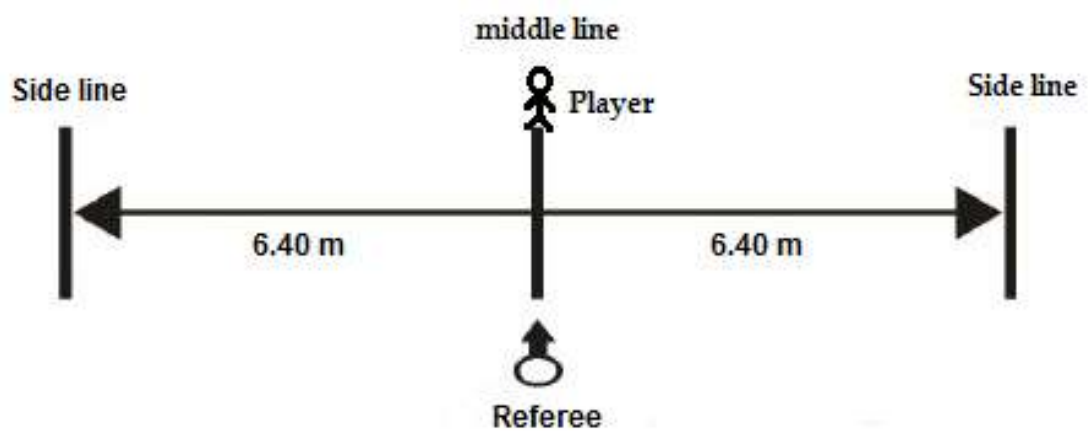

Figure 6. Nelson Test for response movement time

One-handed Medicine Ball Push "2kgs"

The player stands behind the start line putting the ball above one of her palms, then pushes the ball to the farthest point using first her right hand then the left. The attempt is recorded to the closest $1 \mathrm{~cm}$ from the closest point to the start line (Allawi \& Radwan, 2001).

\section{Standing Board Jump Test}

The player stands behind the start line, upon hearing the whistle she jumps to the farthest point she can reach. The distance she jumped is measure from the start line (inside edge) to the last point the player reached close to the start line (Al-Tikriti \& Al-Hajjar, 2012)

- $3 \times 3$ basketball matches were also recorded from the first round of the league for the season 2020/2021, in which the research sample participated using Samsung HD camera to analyze the technical variable, the offensive move without a ball (effective and ineffective) with all its movements "Quick Start, Change of Pace, Change of direction, Jump Stop, stride stop, Jump and Land, Pivot and Turn forward and backward" using Utilius ${ }^{\circledR}$ vs advanced analysis program (4.5.8), as in Figure 7.

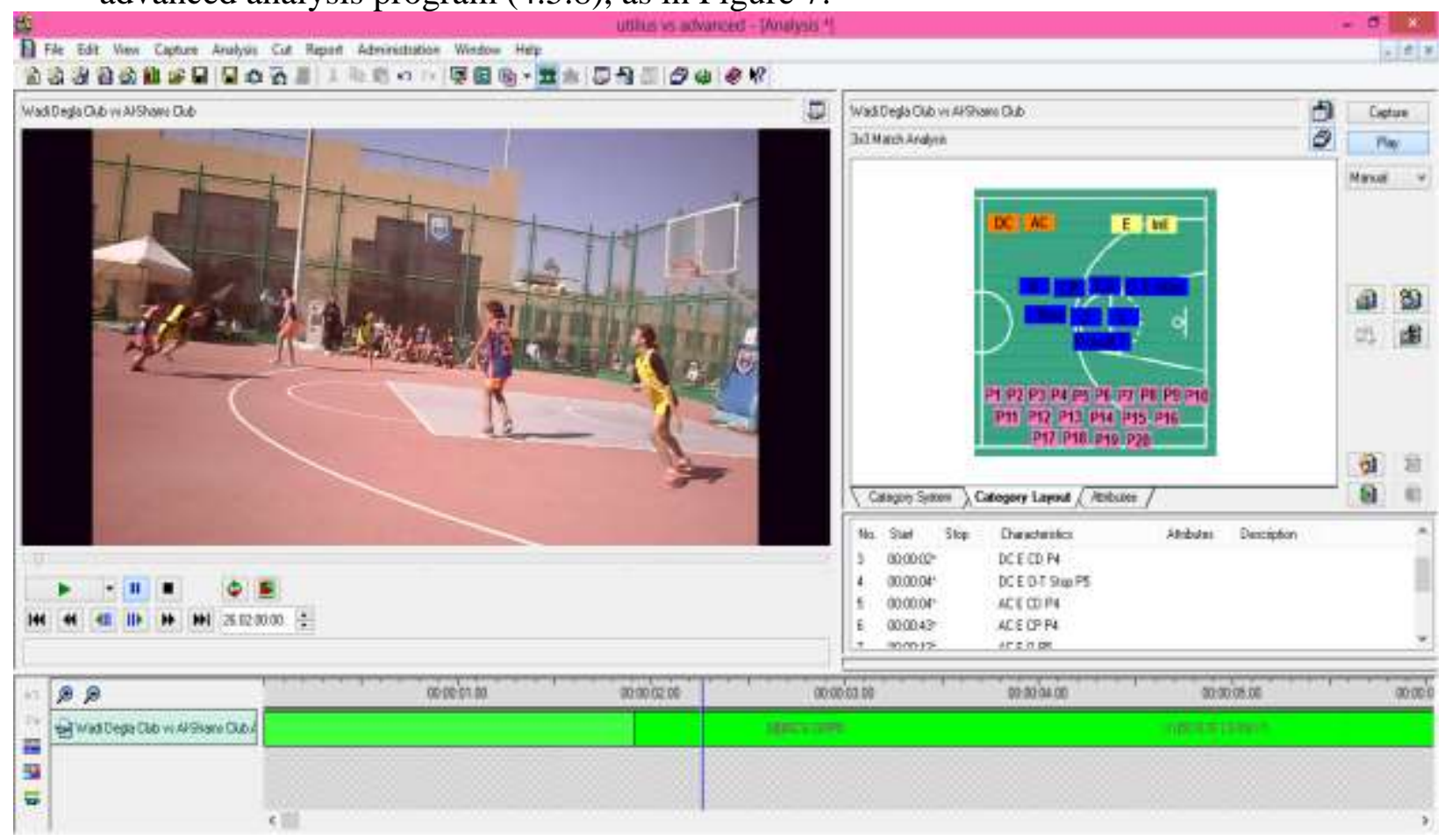

Figure 7. Utilius ${ }^{\circledR}$ vs advanced program analyzing offensive move without a ball 


\section{Notice:}

- Effective offensive move without a ball measurement for the player:

It is her movement using any of the offensive moves without a ball skill at a pace enabling her to outrun the defense player watching her, allowing a good chance to freely receive the ball from her colleague and shoot.

\section{- Ineffective offensive move without a ball measurement for the player:}

It is her movement using any of the offensive moves without a ball skill at a pace hindering her to outrun the defense player watching her, preventing a good chance to freely receive the ball from her colleague and shoot.

- The validity of all physical variables affecting the offensive move without a ball skill and the tests measuring them using content validity have been confirmed through the reference survey of scientific references; as well as the validity of the experts by presenting the variables and tests measuring and approving them (Allawi \& Radwan, 2001; Al-Tikriti \& Al-Hajjar, 2012; Clark, et al.,2010; Gambetta, 2007; Haff \& Triplett, 2016; Hassanein, 1987; Majeed, 1998;Moawad, 2003; Zedan, 2014).

- Also, the validity of the offensive move without a ball skill content and movements included using content validity through the reference survey of scientific references (Arumugam, 2020; Fawzy, 2014; Moawad, 2003); offensive move without a ball was divided with all its inclusions into effective and ineffective, so that this variable is measured in $3 \times 3$ matches determining the extent to which the skill is improved by increasing the number of effective moves and decreasing the number of ineffective moves and vice versa; basketball experts were counselled and they approved this division.

- The reliability of these physical and technical tests was also confirmed by Test-Retest method with a time difference of (14) days between the first and second application, on a sample randomly selected from the research community and outside the research sample, consisting of (5) players "Pilot Sample".

- Pilot experience was run on July $29^{\text {th }}$ and $30^{\text {th }}, 2020$. on a randomly selected sample from the research community and outside the research sample of (5) female players, aiming at identifying the adequacy of physical and technical tests with practical reality and their suitability for this age group, identifying the problems and obstacles that may occur during the application of the training units trying to find appropriate solutions. It is clear from the pilot experience that all physical and technical tests used are valid, and there are no problems or obstacles preventing the application of the training units.

- Technical Pre-measurement (3x3 match) was applied. In the next day, physical premeasurements were applied (Numbered Circles Test, Illinois Agility Test, 10-meter Sprint Test, 5-0 - 5 meter Sprinting Test, Star Excursion Balance Test, Nelson Test for response movement time, One-handed Medicine Ball Push "2kgs", Standing Board Jump Test) on basketball female junior players, experimental research group, before applying the experimental program for acceleration and deceleration power on August $15^{\text {th }}$ and $16^{\text {th }}$, 2020.

- Inter-measurements were applied (technical - physical) on basketball female junior players, experimental research group, identifying continuously the extent and effect of the training program on them. Inter-measurements were as followed:

- First inter-measurement: after two months from applying the program, 3x3 match technical was measured; in the next day, physical 10-meter sprint test to measure 
acceleration and $5-0-5$ meter sprint test were measured to measure deceleration on October $16^{\text {th }}$ and $17^{\text {th }}, 2020$.

- Second inter-measurement: after two months and a half from applying the program, 3x3 match technical was measured; in the next day, physical 10-meter sprint test to test acceleration and $5-0-5$ meter sprint test were measured to measure deceleration on October $30^{\text {th }}$ and $31^{\text {th }}, 2020$.

- Third inter-measurement: after three months from applying the program, 3x3 match technical was measured; in the next day, physical 10-meter sprint test to test acceleration and $5-0-5$ meter sprint test were measured to measure deceleration on November $13^{\text {th }}$ and $14^{\text {th }}, 2020$.

- Fourth inter-measurement: after three months and a half from applying the program, 3x3 match technical was measured; in the next day, physical 10-meter sprint test to test acceleration and 5 -0 -5 meter sprint test were measured to measure deceleration on December $4^{\text {th }}$ and $5^{\text {th }}, 2020$.

- Technical post-measurement $(3 \times 3$ match $)$ was applied, in the next day physical postmeasurement (10-meter sprint test, $5-0-5$ meter sprint test) was applied on basketball female junior players, experimental research group, after applying the training program of acceleration and deceleration power exercises for four months, on December $18^{\text {th }}$ and $19^{\text {th }}, 2020$.

- Players were made sure not to participate in the training 24 hours before the tests, also warm-ups were applied before the tests.

- All physical tests took place on basketball courts in Wadi Degla - Maadi Branch, Egypt.

\subsection{Training Program}

- The proposed program applied acceleration and deceleration power training for four months (16) weeks, with (3) training units per week with a total of (48) units, distributed (12) units in the special preparation period and (12) units in the pre-match preparation period and (24) units in the matches period of the training season. The time of the training unit is (90) minutes, with total time of (4320) minutes on the experimental research group, female juniors under 10 years old from August 17 $7^{\text {th }}, 2020$ to December $16^{\text {th }}, 2020$ on the basketball courts in Wadi Degla Club, Maadi branch. The training program included a set of legs power exercises (Plyometric Exercises) strengthening legs' muscle affecting the development of the acceleration and deceleration element during the special preparation period, pre-matches preparation, and the first month of the match, with (2) training units per week; Then the acceleration and deceleration exercises were applied in the last week of the special preparation period, then continued in the pre-match preparation period by (3) units per week. Acceleration and deceleration exercises continued during matches period too with (3) training units per week, except at match week with only (2) training units to reduce the load before the match. Table 1 shows Plyometric Exercises and the acceleration and deceleration exercises used in the program.

- Using low-intensity interval training method ranging between (60: 80\%) being more suitable for the development of performance endurance and muscular power. Also, highintensity interval training method was used ranging between $(80: 90 \%)$ at the maximum a player can perform being more suitable for the development of both the acceleration and deceleration element and suitable for technical and tactical part (Hammad, 2010; Zedan, 2014). 
- The loads used in the program are average, less than the maximum, and maximum, following a ripple (3:1) distributing the degrees of training loads in the weeks and also training units, being more suitable for juniors (Saleh, 2019).

- The percentage of Physical preparation (40\%), technical preparation (40\%), and tactical preparation $(20 \%)$ in the special preparation period. Physical preparation (30\%), technical preparation $(30 \%)$, and tactical preparation $(40 \%)$ in the pre-match preparation period. Yet, during match period, physical preparation (10\%), technical preparation (30\%) and tactical preparation (60\%) (Al-bik \& Mohamed, 1995).

\section{Table 1. Power, Acceleration and Deceleration Exercises in the Training Program}

\begin{tabular}{|c|c|c|}
\hline Plyometric Drills * & Acceleration Drills ** & Deceleration Drills ** \\
\hline $\begin{array}{l}\text { - wall Squats } \\
\text { - Calf Raises } \\
\text { - Split Squats } \\
\text { - Lunge Walks } \\
\text { - Tuck Jumps } \\
\text { - Broad Jumps } \\
\text { - Cycling Split Squat Jumps } \\
\text { - Lateral bounds } \\
\text { - Vertical Jump- Singles, Land on both Feet } \\
\text { - Long Jump- Singles, Land on both Feet } \\
\text { - Lateral Jump- Singles, Land on both Feet } \\
\text { - Vertical Jump- Singles, Land on one foot } \\
\text { - Vertical Jumps- multiples land on both feet } \\
\text { - 90 Turn Vertical Jump- singles, both feet } \\
\text { - Long Jump- Singles, Land on one foot } \\
\text { - Long Jumps- multiples, land on both feet } \\
\text { - Lateral Jump- Singles, Land on one foot } \\
\text { - Lateral Jumps- multiples same Direction, Land on both } \\
\text { feet } \\
\text { - Vertical Jump (90 turn)- Singles, one Foot } \\
\text { - Vertical Jumps (90॰ turn)- multiples, both feet } \\
\text { - Long Jumps- multiples, land on one foot } \\
\text { - Forward Jump over Barrier- multiples, Land on both } \\
\text { feet } \\
\text { - Forward Jump over Barrier- Singles, Land on one foot } \\
\text { - Lateral Hurdle Hops Full Cycling Split Squat Jumps }\end{array}$ & $\begin{array}{l}\text { - Partner Assisted- March } \\
\text { - Partner Release Sprints } \\
\text { - Face and chase } \\
\text { - Resisted Sprints } \\
\text { - Med Ball Starts } \\
\text { - Run Start } \\
\text { - Lunge Start } \\
\text { - Side Lunge Start } \\
\text { - Sitting } \\
\text { - Push up } \\
\text { - Ball Drop } \\
\text { - Chase Starts } \\
\text { - Jump Back Starts } \\
\text { - Various Starting Positions: } \\
\text { a- Laying on back } \\
\text { b- Push-up "up position" } \\
\text { c- Push up "down } \\
\text { d- Position" } \\
\text { Seated "Facing } \\
\text { e- Sorward" } \\
\text { feated "Facing } \\
\text { f- Fackward" }\end{array}$ & $\begin{array}{l}\text { - Sprint - Front Hold }{ }^{1} \\
\text {-Sprint - Front Hold }{ }^{2} \\
\text {-Sprint- circle } \\
\text {-Sprint- Lateral hold } \\
\text {-Sprint-Sudden deceleration } \\
\text {-5 m acceleration - sudden } \\
\text { deceleration } \\
\text {-1/2 speeds - Hold } \\
\text {-Sprint forward and } \\
\text { decelerate; sprint back and } \\
\text { Hold } \\
\text {-L - pattern agility } \\
\text {-W - pattern agility }\end{array}$ \\
\hline
\end{tabular}

Note: (*) Intensity: 60- 75\%, Reps: 8-10 or 30 sec., Sets: 1-2, Rest: 1-2 mins; (**) Intensity: 90100\%, Reps: 1, Sets: 3-5, Rest: 60-90 secs

\subsection{Statistical Analysis}

(Brewer, 2017; Brown \& Ferrigno, 2014; Chu \& Meyer, 2013)

IBM SPSS version (24) was used to perform the statistical processing for the research. The normality of the research sample was revealed before staring, using the Kolmogorov-Smirnova ${ }^{\text {a }}$ test determining the use of parametric or nonparametric statistics (significance level is P-value) for the experimental group in the "height, weight, age, training age, leg coordination, right arm power, left arm power, legs power, acceleration, deceleration, agility, legs response movement time, right leg dynamic balance, left leg dynamic balance, effective offensive move without a ball in a match, ineffective offensive move without a ball in a match" variables $=(0.14,0.02$, $0.04,0.00,0.01,0.06,0.00,0.01,0.20,0.00,0.20,0.20,0.03,0.20,0.04,0.02)$. Through this, 
found that $\mathrm{P}$-value sig. $\leq 0.05$ in most of the variables, meaning using non-parametric statistics: Friedman Test, calculating differences between the pre-measurement, inter, and postmeasurement of the experimental group, and Wilcoxon signed- rank Test, calculating differences between each of the two measurements together separate and to examine where the differences actually occur with a Bonferroni adjustment on the results (significance level is P-value) 0.05/15 $=0.003$.

\section{Results:}

1- Acceleration and deceleration level results of female junior basketball players':

Table 2. Significance of differences between pre, inter, and post-measurements in acceleration variable

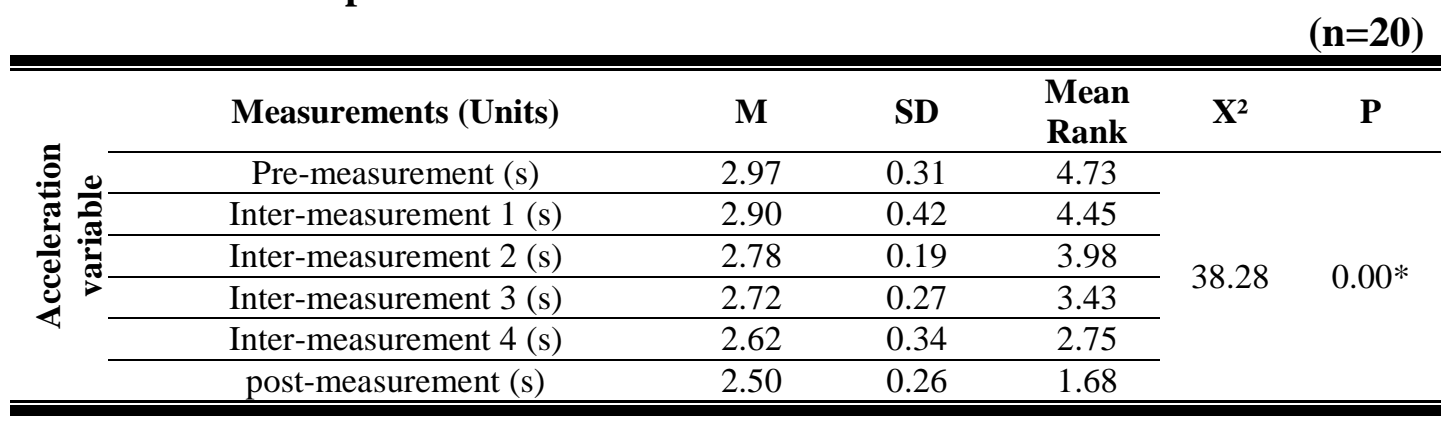

* Significant difference between pre, interphase and post measurements $p \leq 0.05$

Table 2 results indicate statistically significant differences between pre, inter, and postmeasurements of the experimental group in the acceleration variable, as (P-value $<0.05$ ) indicating statistically significant differences in acceleration variable between pre and inter $(1,2$, $3,4)$ and post-measurements. In order to identify and define the source of any measurement differences, Wilcoxon $\mathrm{W}$ test will be applied to calculate the differences between each of the two measurements as follows in Table 3.

Table 3. Post hoc analysis with Wilcoxon signed-rank tests for pre, inter, and postMeasurements in acceleration variable

\begin{tabular}{|c|c|c|c|c|c|c|c|}
\hline \multirow{17}{*}{ 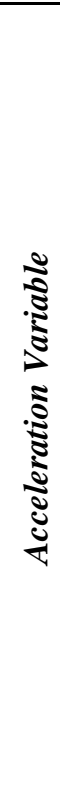 } & Measurement(1) - Measurement(2) & direction & $n$ & $\begin{array}{l}\text { Mean } \\
\text { Rank }\end{array}$ & $\begin{array}{c}\text { Sum of } \\
\text { Ranks }\end{array}$ & $Z$ & $\frac{(\mathrm{n}=20}{P}$ \\
\hline & \multirow{4}{*}{ Pre-Inter (1) } & - & 10 & 10.75 & 107.50 & \multirow{4}{*}{-0.503} & \multirow{4}{*}{0.615} \\
\hline & & + & 9 & 9.17 & 82.50 & & \\
\hline & & $=$ & 1 & & & & \\
\hline & & sum & 20 & & & & \\
\hline & \multirow{4}{*}{ Pre-Inter (2) } & - & 14 & 11.64 & 163.00 & \multirow{4}{*}{-2.165} & \multirow{4}{*}{0.030} \\
\hline & & + & 6 & 7.83 & 47.00 & & \\
\hline & & $=$ & 0 & & & & \\
\hline & & sum & 20 & & & & \\
\hline & \multirow{4}{*}{ Pre-Inter (3) } & - & 14 & 12.64 & 177.00 & \multirow{4}{*}{-2.689} & \multirow{4}{*}{0.007} \\
\hline & & + & 6 & 5.50 & 33.00 & & \\
\hline & & $=$ & 0 & & & & \\
\hline & & sum & 20 & & & & \\
\hline & \multirow{4}{*}{ Pre-Inter (4) } & - & 17 & 11.06 & 188.00 & \multirow{4}{*}{-3.099} & \multirow{4}{*}{$0.002 *$} \\
\hline & & + & 3 & 7.33 & 22.00 & & \\
\hline & & $=$ & 0 & & & & \\
\hline & & sum & 20 & & & & \\
\hline
\end{tabular}




\begin{tabular}{|c|c|c|c|c|c|c|}
\hline \multirow{4}{*}{ Pre - post } & - & 19 & 11.00 & 209.00 & \multirow{4}{*}{-3.883} & \multirow{4}{*}{$0.000 *$} \\
\hline & + & 1 & 1.00 & 1.00 & & \\
\hline & $=$ & 0 & & & & \\
\hline & sum & 20 & & & & \\
\hline \multirow{4}{*}{ Inter(1) - Inter(2) } & - & 13 & 8.31 & 108.00 & \multirow{4}{*}{-1.492} & \multirow{4}{*}{0.136} \\
\hline & + & 4 & 11.25 & 45.00 & & \\
\hline & $=$ & 3 & & & & \\
\hline & sum & 20 & & & & \\
\hline \multirow{4}{*}{ Inter(1) - Inter(3) } & - & 14 & 10.64 & 149.00 & \multirow{4}{*}{-2.174} & \multirow{4}{*}{0.030} \\
\hline & + & 5 & 8.20 & 41.00 & & \\
\hline & $=$ & 1 & & & & \\
\hline & sum & 20 & & & & \\
\hline \multirow{4}{*}{ Inter(1) - Inter(4) } & - & 15 & 11.10 & 166.50 & \multirow{4}{*}{-2.297} & \multirow{4}{*}{0.022} \\
\hline & + & 5 & 8.70 & 43.50 & & \\
\hline & $=$ & 0 & & & & \\
\hline & sum & 20 & & & & \\
\hline \multirow{4}{*}{ Inter(1) - post } & - & 15 & 11.27 & 169.00 & \multirow{4}{*}{-2.978} & \multirow{4}{*}{$0.003 *$} \\
\hline & + & 4 & 5.25 & 21.00 & & \\
\hline & $=$ & 1 & & & & \\
\hline & sum & 20 & & & & \\
\hline \multirow{4}{*}{ Inter(2) - Inter(3) } & - & 14 & 8.86 & 124.00 & \multirow{4}{*}{-1.167} & \multirow{4}{*}{0.243} \\
\hline & + & 5 & 13.20 & 66.00 & & \\
\hline & $=$ & 1 & & & & \\
\hline & sum & 20 & & & & \\
\hline \multirow{4}{*}{ Inter(2) - Inter(4) } & - & 14 & 10.75 & 150.50 & \multirow{4}{*}{-2.235} & \multirow{4}{*}{0.025} \\
\hline & + & 5 & 7.90 & 39.50 & & \\
\hline & $=$ & 1 & & & & \\
\hline & sum & 20 & & & & \\
\hline \multirow{4}{*}{ Inter(2) - post } & - & 19 & 10.37 & 197.00 & \multirow{4}{*}{-3.436} & \multirow{4}{*}{$0.001 *$} \\
\hline & + & 1 & & & & \\
\hline & $=$ & 0 & & & & \\
\hline & sum & 20 & & & & \\
\hline & - & 14 & 9.21 & 129.00 & & \\
\hline Inter(3) - Inter(4) & + & 4 & 10.50 & 42.00 & -1895 & 0.058 \\
\hline Inter(3)-Inter(4) & $=$ & 2 & & & -1.895 & 0.058 \\
\hline & sum & 20 & & & & \\
\hline & - & 15 & 9.33 & 140.00 & & \\
\hline & + & 2 & 6.50 & 13.00 & -3.007 & $0,003 *$ \\
\hline Inter(3) - post & $=$ & 3 & & & -3.001 & $0.003^{*}$ \\
\hline & sum & 20 & & & & \\
\hline & - & 15 & 8.90 & 133.50 & & \\
\hline & + & 2 & 9.75 & 19.50 & 2700 & 0007 \\
\hline Inter(4)-post & $=$ & 3 & & & -2.100 & 0.001 \\
\hline & sum & 20 & & & & \\
\hline
\end{tabular}

*Bonferroni correction for multiple tests applied, resulting in a significance level set at $p \leq 0.003$

Table 3 results indicate statistically significant differences between pre- and intermeasurement (4) of acceleration in favor of the inter-measurement (4) having the lowest mean. Also, statistically significant differences between pre- and post-measurements of acceleration in 
favor of post-measurement having the lowest mean. There are statistically significant differences between post- and inter-measurement (1) of acceleration in favor of the post-measurement having the lowest mean. Also, statistically significant differences between post- and intermeasurement (2) in favor of post-measurement having the lowest mean, and statistically significant differences between post- and inter-measurement (3) of acceleration in favor of postmeasurement having the lowest mean.

Table 4. Significance of differences between pre, inter, and post-measurements in deceleration variable

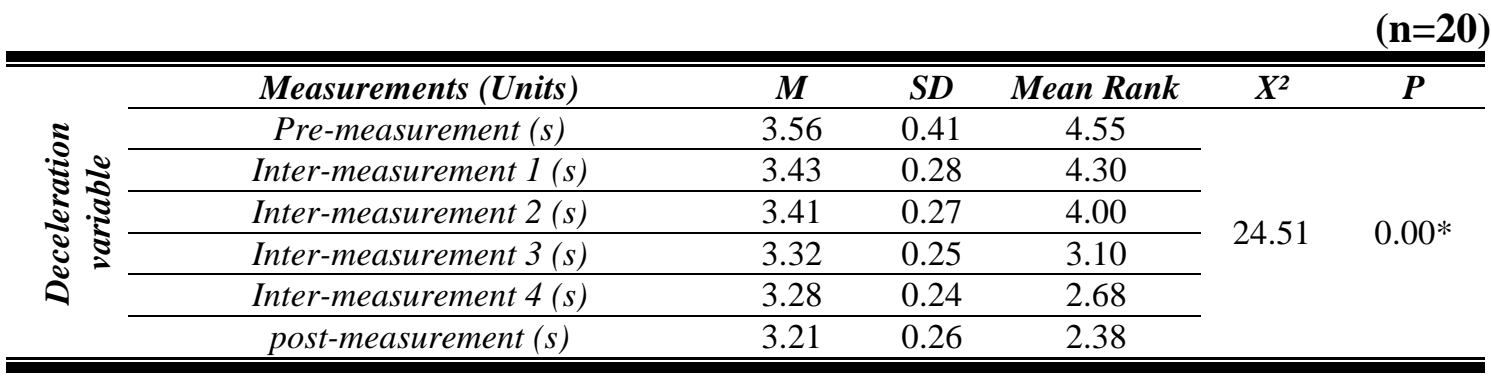

* Significant difference between pre, interphase and post measurements $p \leq 0.05$

Table 4 results indicate statistically significant differences between pre, inter, and postmeasurements for the experimental group in deceleration variable, as ( $\mathrm{P}$-value $<0.05)$ indicating statistically significant differences between pre, inter $(1,2,3,4)$ and post-measurements in deceleration variable. To identify the source of difference in favor of any measurement, Wilcoxon W Test will be applied to calculate the differences between each two measurements as followed in Table 5 .

Table 5. Post hoc analysis with Wilcoxon signed-rank tests for pre, inter, and postmeasurements in deceleration variable

\begin{tabular}{|c|c|c|c|c|c|c|c|}
\hline \multirow{20}{*}{ 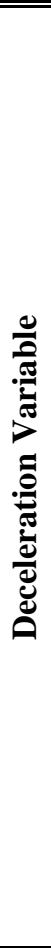 } & Measurement(1) - Measurement(2) & direction & $\mathbf{n}$ & $\begin{array}{l}\text { Mean } \\
\text { Rank }\end{array}$ & $\begin{array}{c}\text { Sum of } \\
\text { Ranks }\end{array}$ & $\mathbf{Z}$ & $\mathbf{P}$ \\
\hline & \multirow{4}{*}{ Pre - Inter (1) } & - & 9 & 13.11 & 118.00 & \multirow{4}{*}{-0.926} & \multirow{4}{*}{0.300} \\
\hline & & + & 10 & 7.20 & 72.00 & & \\
\hline & & $=$ & 1 & & & & \\
\hline & & sum & 20 & & & & \\
\hline & \multirow{4}{*}{ Pre - Inter (2) } & - & 11 & 8.91 & 98.00 & \multirow{4}{*}{-1.551} & \multirow{4}{*}{0.121} \\
\hline & & + & 5 & & & & \\
\hline & & $=$ & 4 & & & & \\
\hline & & sum & 20 & & & & \\
\hline & \multirow{4}{*}{ Pre - Inter (3) } & - & 13 & 11.15 & 145.00 & \multirow{4}{*}{-2.592} & \multirow{4}{*}{0.010} \\
\hline & & + & 5 & & & & \\
\hline & & $=$ & 2 & & & & \\
\hline & & sum & 20 & & & & \\
\hline & \multirow{4}{*}{ Pre - Inter(4) } & - & 16 & 10.03 & 160.50 & \multirow{4}{*}{-3.267} & \multirow{4}{*}{$0.001 *$} \\
\hline & & + & 2 & & & & \\
\hline & & $=$ & 2 & & & & \\
\hline & & sum & 20 & & & & \\
\hline & \multirow{3}{*}{ Pre - post } & - & 17 & 10.88 & 185.00 & \multirow{3}{*}{-3.622} & \multirow{3}{*}{$0.000 *$} \\
\hline & & + & 2 & 2.50 & 5.00 & & \\
\hline & & $=$ & 1 & & & & \\
\hline
\end{tabular}




\begin{tabular}{|c|c|c|c|c|c|c|}
\hline & sum & 20 & & & & \\
\hline \multirow{4}{*}{ Inter(1) - Inter(2) } & - & 12 & 8.46 & 101.50 & \multirow{4}{*}{-0.697} & \multirow{4}{*}{0.486} \\
\hline & + & 6 & 11.58 & 69.50 & & \\
\hline & $=$ & 2 & & & & \\
\hline & sum & 20 & & & & \\
\hline \multirow{4}{*}{ Inter(1) - Inter(3) } & - & 14 & 10.32 & 144.50 & \multirow{4}{*}{-1.993} & \multirow{4}{*}{0.046} \\
\hline & + & 5 & 9.10 & 45.50 & & \\
\hline & $=$ & 1 & & & & \\
\hline & sum & 20 & & & & \\
\hline \multirow{4}{*}{ Inter(1) - Inter(4) } & - & 14 & 10.14 & 142.00 & \multirow{4}{*}{-1.892} & \multirow{4}{*}{0.059} \\
\hline & + & 5 & 9.60 & 48.00 & & \\
\hline & $=$ & 1 & & & & \\
\hline & sum & 20 & & & & \\
\hline \multirow{4}{*}{ Inter(1) - post } & - & 13 & 11.38 & 148.00 & \multirow{4}{*}{-2.133} & \multirow{4}{*}{0.033} \\
\hline & + & 6 & 7.00 & 42.00 & & \\
\hline & $=$ & 1 & & & & \\
\hline & sum & 20 & & & & \\
\hline \multirow{4}{*}{ Inter(2) - Inter(3) } & - & 16 & 10.34 & 165.50 & \multirow{4}{*}{-2.838} & \multirow{4}{*}{0.005} \\
\hline & + & 3 & 8.17 & 24.50 & & \\
\hline & $=$ & 1 & & & & \\
\hline & sum & 20 & & & & \\
\hline \multirow{4}{*}{ Inter(2) - Inter(4) } & - & 16 & 11.09 & 177.50 & \multirow{4}{*}{-2.708} & \multirow{4}{*}{0.007} \\
\hline & + & 4 & 8.13 & 32.50 & & \\
\hline & $=$ & 0 & & & & \\
\hline & sum & 20 & & & & \\
\hline \multirow{4}{*}{ Inter(2) - post } & - & 13 & 12.62 & 164.00 & \multirow{4}{*}{-2.778} & \multirow{4}{*}{0.005} \\
\hline & + & 6 & 4.33 & 26.00 & & \\
\hline & $=$ & 1 & & & & \\
\hline & sum & 20 & & & & \\
\hline \multirow{4}{*}{ Inter(3) - Inter(4) } & - & 11 & 8.00 & 88.00 & \multirow{4}{*}{-1.591} & \multirow{4}{*}{0.112} \\
\hline & + & 4 & 8.00 & 32.00 & & \\
\hline & $=$ & 5 & & & & \\
\hline & sum & 20 & & & & \\
\hline \multirow{4}{*}{ Inter(3) - post } & - & 13 & 11.00 & 143.00 & & \\
\hline & + & 6 & 7.83 & 47.00 & -1932 & 0.053 \\
\hline & $=$ & 1 & & & -1.932 & 0.053 \\
\hline & sum & 20 & & & & \\
\hline & - & 13 & 8.77 & 114.00 & & \\
\hline Inter(4) - post & + & 4 & 9.75 & 39.00 & -1776 & 0.076 \\
\hline mert(4)-post & $=$ & 3 & & & -1.170 & 0.070 \\
\hline & sum & 20 & & & & \\
\hline
\end{tabular}

*Bonferroni correction for multiple tests applied, resulting in a significance level set at $p \leq 0.003$

Table 5 results indicate statistically significant differences between pre- and intermeasurement (4) of deceleration in favor of the inter measurement (4) having the lowest mean. Also, statistically significant differences between pre- and post- measurements of deceleration in favor of post-measurement having the lowest mean. 
2- Offensive move without a ball in female junior basketball matches results:

Table 6. Significance of differences between pre, inter, and post-measurements in offensive move without a ball variable (Effective move) in matches

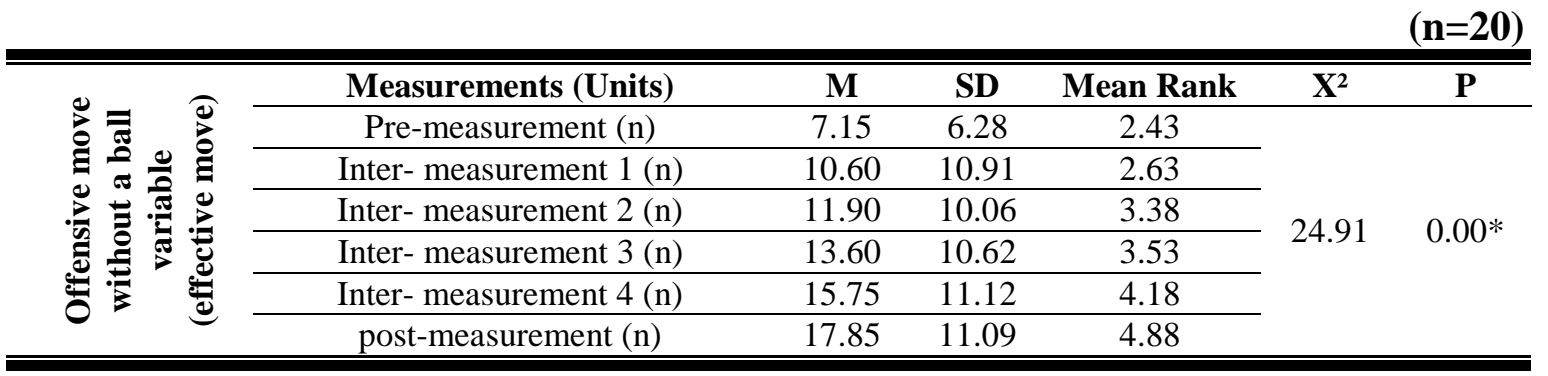

* Significant difference between pre, interphase and post measurements $p \leq 0.05$

Table 6 results indicate statistically significant differences between pre, inter, and postmeasurements for the experimental group in effective offensive move without a ball variable in matches. As (P-value < 0.05), this indicates statistically significant differences between pre, inter $(1,2,3,4)$, and post-measurements in effective offensive move without a ball variable in matches. To identify and define differences in favor of any measurements, Wilcoxon W Test will be applied to calculate differences between each two measurements as followed in Table 7.

Table 7. Post hoc analysis with Wilcoxon signed-rank tests for pre, inter, and post-measurements in offensive move without a ball (Effective move) variable

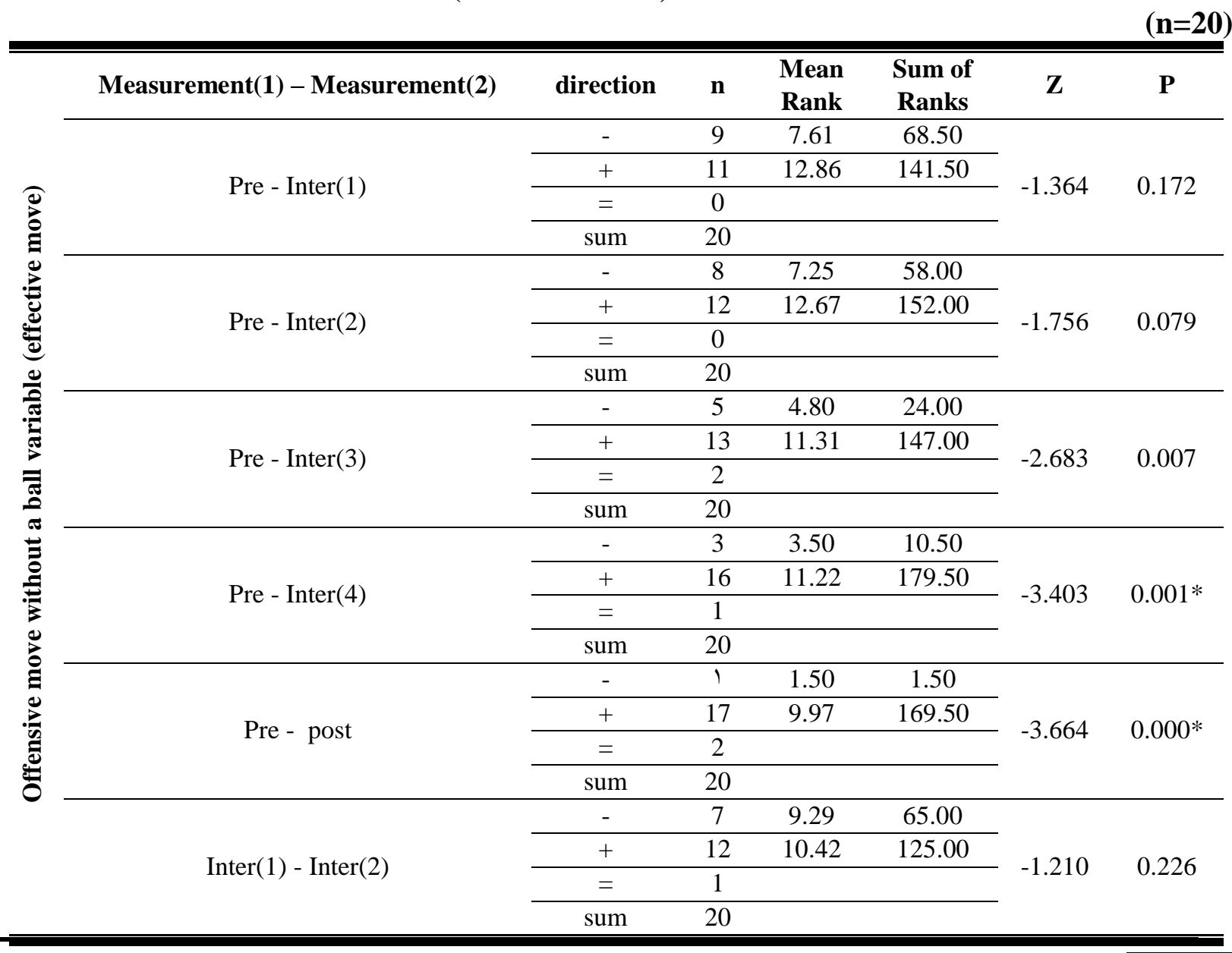




\begin{tabular}{|c|c|c|c|c|c|c|}
\hline \multirow{4}{*}{ Inter(1) - Inter(3) } & - & 7 & 8.93 & 62.50 & \multirow{4}{*}{-1.592} & \multirow{4}{*}{0.111} \\
\hline & + & 13 & 11.35 & 147.50 & & \\
\hline & $=$ & 0 & & & & \\
\hline & sum & 20 & & & & \\
\hline \multirow{4}{*}{ Inter(1) - Inter(4) } & - & 5 & 10.80 & 54.00 & \multirow{4}{*}{-1.906} & \multirow{4}{*}{0.057} \\
\hline & + & 15 & 10.40 & 156.00 & & \\
\hline & $=$ & 0 & & & & \\
\hline & sum & 20 & & & & \\
\hline \multirow{4}{*}{ Inter(1) - post } & - & 2 & 8.75 & 17.50 & \multirow{4}{*}{-3.270} & \multirow{4}{*}{$0.001 *$} \\
\hline & + & 18 & 10.69 & 192.50 & & \\
\hline & $=$ & 0 & & & & \\
\hline & sum & 20 & & & & \\
\hline \multirow{4}{*}{ Inter(2) - Inter(3) } & - & 9 & 10.72 & 96.50 & \multirow{4}{*}{-0.060} & \multirow{4}{*}{0.952} \\
\hline & + & 10 & 9.35 & 93.50 & & \\
\hline & $=$ & 1 & & & & \\
\hline & sum & 20 & & & & \\
\hline \multirow{4}{*}{ Inter(2) - Inter(4) } & - & 9 & 8.17 & 73.50 & \multirow{4}{*}{-0.866} & \multirow{4}{*}{0.386} \\
\hline & + & 10 & 11.65 & 116.50 & & \\
\hline & $=$ & 1 & & & & \\
\hline & sum & 20 & & & & \\
\hline \multirow{4}{*}{ Inter(2) - post } & - & 3 & 6.17 & 18.50 & \multirow{4}{*}{-2.923} & \multirow{4}{*}{$0.003 *$} \\
\hline & + & 15 & 10.17 & 152.50 & & \\
\hline & $=$ & 2 & & & & \\
\hline & sum & 20 & & & & \\
\hline \multirow{4}{*}{ Inter(3) - Inter(4) } & - & 8 & 9.88 & 79.00 & \multirow{4}{*}{-0.971} & \multirow{4}{*}{0.331} \\
\hline & + & 12 & 10.92 & 131.00 & & \\
\hline & $=$ & 0 & & & & \\
\hline & sum & 20 & & & & \\
\hline \multirow{4}{*}{ Inter(3) - post } & - & 5 & 7.50 & 37.50 & \multirow{4}{*}{-2.526} & \multirow{4}{*}{0.012} \\
\hline & + & 15 & 11.50 & 172.50 & & \\
\hline & $=$ & 0 & & & & \\
\hline & sum & 20 & & & & \\
\hline \multirow{4}{*}{ Inter(4) - post } & - & 9 & 9.06 & 81.50 & \multirow{4}{*}{-0.544} & \multirow{4}{*}{0.587} \\
\hline & + & 10 & 10.85 & 108.50 & & \\
\hline & $=$ & 1 & & & & \\
\hline & sum & 20 & & & & \\
\hline
\end{tabular}

*Bonferroni correction for multiple tests applied, resulting in a significance level set at $p \leq 0.003$

Table 7 results indicate statistically significant differences between pre- and intermeasurement (4) of effective offensive move without a ball in favor of inter-measurement (4) with the largest mean. There are statistically significant differences between pre- and postmeasurements of effective offensive move without a ball in favor of post-measurement with the largest mean. Also, statistically significant differences between inter-measurement (1) and postmeasurement of effective offensive move without a ball in favor of post measurement with the largest mean. There are statistically significant differences between inter-measurement (2) and post-measurement of effective offensive move without a ball in favor of post measurement with the largest mean. 
Table 8. Significance of differences between of pre, inter, and post-measurements in offensive move without a ball variable (Ineffective move) in matches

\begin{tabular}{|c|c|c|c|c|c|c|}
\hline \multirow{7}{*}{ 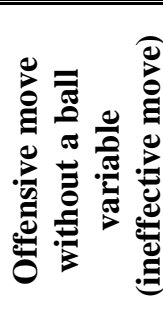 } & Measurements (Units) & $\mathbf{M}$ & SD & $\begin{array}{l}\text { Mean } \\
\text { Rank } \\
\end{array}$ & $\mathbf{X}^{2}$ & $\frac{(n=2}{P}$ \\
\hline & Pre-measurement (n) & 6.00 & 4.76 & 4.88 & \multirow{6}{*}{23.05} & \multirow{6}{*}{$0.00 *$} \\
\hline & Inter- measurement 1 (n) & 4.30 & 4.19 & 4.15 & & \\
\hline & Inter- measurement 2 (n) & 2.80 & 2.63 & 3.40 & & \\
\hline & Inter- measurement 3 (n) & 2.05 & 2.84 & 2.63 & & \\
\hline & Inter- measurement $4(\mathrm{n})$ & 1.60 & 1.39 & 3.00 & & \\
\hline & post-measurement (n) & 1.50 & 1.54 & 2.95 & & \\
\hline
\end{tabular}

* Significant difference between pre, interphase and post measurements $p \leq 0.05$

Table 8 results indicate statistically significant differences between pre, inter, and postmeasurements for the experimental group in ineffective offensive move without a ball variable in matches. As (P-value < 0.05), this indicates statistically significant differences between pre, inter $(1,2,3,4)$, and post-measurements in ineffective offensive move without a ball variable in matches. To identify and define differences in favor of any measurements, Wilcoxon W Test will be applied to calculate differences between each two measurements as followed in Table 9 .

Table 9. Post hoc analysis with Wilcoxon signed-rank tests for pre, inter, and post-measurements in offensive move without a ball variable (Ineffective move) in matches

\begin{tabular}{|c|c|c|c|c|c|c|c|}
\hline \multirow{8}{*}{ 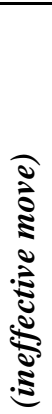 } & Measurement(1) - Measurement(2) & direction & $n$ & $\begin{array}{l}\text { Mean } \\
\text { Rank }\end{array}$ & $\begin{array}{c}\text { Sum of } \\
\text { Ranks }\end{array}$ & $Z$ & $(\mathbf{n}=\mathbf{2 0}$ \\
\hline & \multirow{4}{*}{ Pre - Inter(1) } & - & 13 & 8.96 & 116.50 & \multirow{4}{*}{-1.353} & \multirow{4}{*}{0.176} \\
\hline & & + & 5 & 10.90 & 54.50 & & \\
\hline & & $=$ & 2 & & & & \\
\hline & & sum & 20 & & & & \\
\hline & \multirow{4}{*}{ Pre - Inter(2) } & - & 14 & 12.04 & 168.50 & \multirow{4}{*}{-2.375} & \multirow{4}{*}{0.018} \\
\hline & & + & 6 & 6.92 & 41.50 & & \\
\hline & & $=$ & 0 & & & & \\
\hline \multirow{5}{*}{ 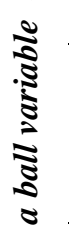 } & & sum & 20 & & & & \\
\hline & \multirow{4}{*}{ Pre - Inter(3) } & - & 16 & 9.66 & 154.50 & \multirow{4}{*}{-2.401} & \multirow{4}{*}{0.016} \\
\hline & & + & 3 & 11.83 & 35.50 & & \\
\hline & & $=$ & 1 & & & & \\
\hline & & sum & 20 & & & & \\
\hline $\mathfrak{3}$ & \multirow{4}{*}{ Pre - Inter(4) } & - & 14 & 9.39 & 131.50 & \multirow{4}{*}{-3.294} & \multirow{4}{*}{$0.001 *$} \\
\hline$\frac{2}{8}$ & & + & 2 & 2.25 & 4.50 & & \\
\hline 3 & & $=$ & 4 & & & & \\
\hline ठे & & sum & 20 & & & & \\
\hline 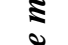 & \multirow{4}{*}{ Pre - post } & - & 16 & 10.50 & 168.00 & \multirow{4}{*}{-3.610} & \multirow{4}{*}{$0.000 *$} \\
\hline. $\overrightarrow{5}$ & & + & 2 & 1.50 & 3.00 & & \\
\hline$\sqrt[5]{2}$ & & $=$ & 2 & & & & \\
\hline 8 & & sum & 20 & & & & \\
\hline & \multirow{3}{*}{ Inter(1) - Inter(2) } & - & 11 & 9.32 & 102.50 & \multirow{3}{*}{-1.235} & \multirow{3}{*}{0.217} \\
\hline & & + & 6 & 8.42 & 50.50 & & \\
\hline & & $=$ & 3 & & & & \\
\hline
\end{tabular}




\begin{tabular}{|c|c|c|c|c|c|c|}
\hline & sum & 20 & & & & \\
\hline \multirow{4}{*}{ Inter(1) - Inter(3) } & - & 14 & 8.29 & 116.00 & \multirow{4}{*}{-2.492} & \multirow{4}{*}{0.013} \\
\hline & + & 2 & 10.00 & 20.00 & & \\
\hline & $=$ & 4 & & & & \\
\hline & sum & 20 & & & & \\
\hline \multirow{4}{*}{ Inter(1) - Inter(4) } & - & 14 & 10.61 & 148.50 & \multirow{4}{*}{-2.164} & \multirow{4}{*}{0.030} \\
\hline & + & 5 & 8.30 & 41.50 & & \\
\hline & $=$ & 1 & & & & \\
\hline & sum & 20 & & & & \\
\hline \multirow{4}{*}{ Inter(1) - post } & - & 10 & 7.30 & 73.00 & \multirow{4}{*}{-2.670} & \multirow{4}{*}{0.008} \\
\hline & + & 2 & 2.50 & 5.00 & & \\
\hline & $=$ & 8 & & & & \\
\hline & sum & 20 & & & & \\
\hline \multirow{4}{*}{ Inter(2) - Inter(3) } & - & 9 & 8.56 & 77.00 & \multirow{4}{*}{-0.970} & \multirow{4}{*}{0.332} \\
\hline & + & 6 & 7.17 & 43.00 & & \\
\hline & $=$ & 5 & & & & \\
\hline & sum & 20 & & & & \\
\hline \multirow{4}{*}{ Inter(2) - Inter(4) } & - & 11 & 10.18 & 112.00 & \multirow{4}{*}{-1.697} & \multirow{4}{*}{0.090} \\
\hline & + & 6 & 6.83 & 41.00 & & \\
\hline & $=$ & 3 & & & & \\
\hline & sum & 20 & & & & \\
\hline \multirow{4}{*}{ Inter(2) - post } & - & 8 & 10.94 & 87.50 & \multirow{4}{*}{-1.581} & \multirow{4}{*}{0.114} \\
\hline & + & 7 & 4.64 & 32.50 & & \\
\hline & $=$ & 5 & & & & \\
\hline & sum & 20 & & & & \\
\hline \multirow{4}{*}{ Inter(3) - Inter(4) } & - & 6 & 11.25 & 67.50 & \multirow{4}{*}{-0.429} & \multirow{4}{*}{0.668} \\
\hline & + & 9 & 5.83 & 52.50 & & \\
\hline & $=$ & 5 & & & & \\
\hline & sum & 20 & & & & \\
\hline \multirow{4}{*}{ Inter(3) - post } & - & 5 & 10.20 & 51.00 & \multirow{4}{*}{-0.095} & \multirow{4}{*}{0.924} \\
\hline & + & 9 & 6.00 & 54.00 & & \\
\hline & $=$ & 6 & & & & \\
\hline & sum & 20 & & & & \\
\hline \multirow{4}{*}{ Inter(4) - post } & - & 10 & 8.65 & 86.50 & \multirow{4}{*}{-0.479} & \multirow{4}{*}{0.632} \\
\hline & + & 7 & 9.50 & 66.50 & & \\
\hline & $=$ & 3 & & & & \\
\hline & sum & 20 & & & & \\
\hline
\end{tabular}

*Bonferroni correction for multiple tests applied, resulting in a significance level set at $p \leq 0.003$

Table 9 results indicate statistically significant differences between pre- and intermeasurement (4) of ineffective offensive move without a ball in favor of inter-measurement (4) with the least mean. There are statistically significant differences between pre- and postmeasurements of ineffective offensive move without a ball in favor of post-measurement with the least mean.

\section{Discussion:}

\section{1- Acceleration and deceleration level for female juniors' basketball players:}

Tables 2 and 3 results indicate an improvement in the level of acceleration in the research sample reaching statistical significance after three and a half months "inter-measurement (4)", continuing for more than four months "post-measurement" from the application of the training 
program, including acceleration and deceleration power exercises. This improvement was in favor of the post-measurement with the least time. Tables 4 and 5 results also indicate an improvement in the level of deceleration in the research sample reaching statistical significance after three and a half months "inter-measurement (4)" continuing for more than four months "post-measurement" from the application of the training program, including acceleration and deceleration power exercises. This improvement was in favor of the post-measurement with the least time.

The researcher attributes these results to the level of acceleration and deceleration improvement in the research sample after the application of proposed training program, including plyometric exercises with selected body weight, which works on developing the element of power for both legs in the direction of acceleration, deceleration, landing and stopping, which lasted three months with two training units per week. These exercises positively affected the strengthening of legs' muscles helping players generate more energy when touching the surface of court, improving the acceleration process, as well as generating strong muscle contractions which improves the ability to slow down and stop without causing injuries.

These results are in agreement with Aksović et al. (2020) study stating that plyometric training has positive effects on developing sprint power for junior basketball players.

Dawes and Lentz (2012) indicate a great relationship between lower limbs power and acceleration and deceleration, as the ability to generate greater ground reaction power when striking with the foot allows the achievement of longer strides, hence improving. When the athlete pushes his foot back and down, the interactions between the foot and the ground will propel the athlete forward. Based on this interaction, it seems appropriate to train the muscles of the lower limbs directly responsible for generating power of the foot strides, specifically those muscles surrounding the hip. Hamstring muscles also play a major role in slowing the lower part of the leg in preparation for contact with the ground. Body weight strengthening exercises such as different types of squats as well as multi-directional lunges and strides are preferred for similarity with the mechanics of sprinting.

In this regard, Vázquez-Guerrero et al. (2018) stresses that training programs should include power training to counter eccentric muscle work leading to a noticeable mechanical stress on basketball players caused by deceleration processes, in order to prevent injuries.

As stated by Ashton and Jones (2019), the training program includes plyometric exercises, to develop explosive power and enhance leg rigidity, it works mainly on making the runner's legs more solid and capable of generating energy from the surface of the earth.

The researcher attributes these results also in acceleration and deceleration level improvement in the research sample to applying the training program, which includes various exercises of acceleration and deceleration applied after applying power exercises for three weeks, they lasted for three months and a week with three units per week, except in the match week they were reduced to only two units. These exercises had a positive and effective impact on the level of acceleration and deceleration.

These results are consistent with what Fawzy (2014) mentioned; for the player to be able to move well and perform the accelerations and decelerations appropriately, he must be trained to quickly start from standing or walking stances, and to stop suddenly from fast or medium sprinting, and change sprinting speed from slow or medium to fast and vice versa, so as to change the sprint speed from maximum to slow or medium speed.

Gels (2019) states that players must be taught to change speed from fast to slow and then reaccelerate again, as well as stopping and deceleration, with exercises included in the program to 
improve their acceleration and deceleration.

Loturco et al. (2019) study results indicate that players with higher acceleration rates were able to run faster (over short distances), and achieve higher directional speed than their slower counterparts.

Through the previous presentation of tables 2, 3, 4, and 5 results, it is clear that the first hypothesis was fulfilled.

2- Offensive move without a ball level in female junior basketball matches:

Tables 6 and 7 results indicate an improvement in the level of effective offensive move without a ball in the research sample, reaching the statistical significance after three and a half months "inter-measurement (4)". The statistically significant improvement continued after four months "post-measurement" of the program's application, including acceleration and deceleration power exercises. This improvement was in favor of post-measurement with the largest number of effective movements. Tables 8 and 9 results also indicate a decrease in the level of ineffective offensive move without a ball in the research sample reaching after three and a half months "inter-measurement (4)" as well as after four months "post-measurement" from the application of the training program, including acceleration and deceleration power exercises. This decrease was in favor of the post-measurement with the lowest number of ineffective movements.

The researcher attributes these results in the level of effective offensive move without a ball improvement and the decrease in ineffective offensive move without a ball in the research sample, after the application of proposed training program for a period of four months, including exercises to strengthen legs muscles, acceleration and deceleration exercises that work on helping players and increase control on quick start in a short distance, and also increases their power to stop suddenly without causing injuries. Also, to reduce their willingness to quickly change direction in a short distance and time, increasing their agile offensive moves on court, hence increasing chances of escaping from defenders.

These findings are consistent with study results from Arumugam et al. (2020), stating that eight weeks of foot speed training improves both foot movement and pace for players.

These results are also consistent with Zushi (2006) study results, stating that plyometric, using drop jump and medicine ball throw, are effective training methods for improving jumping, foot movement and chest passing ability among competitive basketball players.

Kumar (2014) states that correct footwork is the basis of basketball. The player's control foot movement from quick start in short distances, balance in landing, and change of pace to the front and back, makes the player less prone to injury risks and better on the court.

In addition, the proposed training program includes acceleration and deceleration exercises increasing players' power to move well on court for the similarity of the movement mechanics in acceleration, whether forward, to the side or backward. As well as the deceleration mechanic to prepare for a change of direction or sudden stop or landing from jumping with the mechanics of good offensive move on court without a ball during matches, which players resort to as to escape from defenders to receive the ball and score points.

This comes in agreement with Izzo and Sopranzetti (2010) study, pointing that during matches the player does not play clearly and at a conjoined rate, yet requires a large number of acceleration and deceleration stances.

Vázquez-Guerrero et al. (2018) asserts that producing acceleration and deceleration in different axes corresponding to different skills such as sprinting, change of direction or jumping, is vital for gaining advantages in team sports. 
Young and Coratella (2021) point that, players must speed up and slow down to escape defenders and receive the ball.

Izzo and Lo Castro (2015) state that, the different acceleration and deceleration power of athletes determines the overall quality of each player, their ability to circumvent, win 1 vs 1 , and score points.

As per the afore presentation of tables 6, 7, 8, and 9 results, it is clear that the second hypothesis has been fulfilled.

\section{Conclusion:}

In light of the research's objectives and hypotheses and the method used, within the limits of the research sample, through statistical analysis, and based on achieved results, it can be concluded that the training program for acceleration and deceleration power exercises has a positive effect in improving the level of acceleration and deceleration for female junior basketball players. It also has a positive effect in improving the level of effective offensive move without a ball and decreasing the level of ineffective offensive move without a ball in female junior basketball matches.

Therefore, the researcher recommends applying acceleration and deceleration power exercises in the training program, to improve the players' ability to move offensively without a ball, enhancing their ability to circumvent and outmaneuver the opponent easily, receive the ball, and score points, which increases the team's efficiency and superiority and win matches. she also recommends the use of these exercises, "the power of acceleration and deceleration", especially for juniors, as it helps greatly in improving their movements on the court, being one of the first skills that must be learned and acquired for juniors, having a direct effect on increasing their pace and balance while performing all other basketball skills.

\section{Reference:}

Aksović, N., Berić, D., Kocić, M., Jakovljević, S., \& Milanović, F. (2020). Plyometric training and sprint abilities of young basketball players. Facta Universitatis, Series: Physical Education and Sport, 539-548.

Al-bik, A. F., \& Mohamed, SH. A. (1995). Training Planning in Basketball. Alexandria, Egypt: Al Maarif Printing.

Allawi, M. H., \& Radwan, M. N. (2001). Kinetic Performance Tests. Cairo, Egypt: Dar Elfikr Elarabi.

Al-Tikriti, W. Y., \& Al-Hajjar, Y. T. (2012). The complete encyclopedia in the physical preparation for women. Alexandria, Egypt: Dar Alwafaa.

American Sport Education Program. (2007). Coaching youth basketball. Human Kinetics 1.

Arumugam, S., Vigneshwaran, G., Kumar, V. \& Suriya, P. (2020). Effect of Quick Footwork

Drills on Footwork and Quickness among Soccer Players. Gorteria Journal, 33(12), 422-428.

Ashton, J., \& Jones, P. A. (2019). The reliability of using a laser device to assess deceleration ability. Sports, 7(8), 191.

Brewer, C. (2017). Athletic Movement Skills: training for sports performance. Human Kinetics.

Brown, L., \& Ferrigno, V. (Eds.). (2014). Training for speed, agility, and quickness, 3E. Human Kinetics.

Chu, D. A., \& Meyer, G. C. (2013). Plyometrics. Human kinetics.

Clark, M., Lucett, S., \& Kirkendall, D. T. (2010). NASM's essentials of sports performance training. Lippincott Williams \& Wilkins. 
Conte, D., Straigis, E., Clemente, F. M., Gómez, M. Á., \& Tessitore, A. (2019). Performance profile and game-related statistics of FIBA 3x3 Basketball World Cup 2017. Biology of sport, 36(2), 149.

Dawes, J., \& Lentz, D. (2012). Methods of developing power to improve acceleration for the non-track athlete. Strength \& Conditioning Journal, 34(6), 44-51.

Emory \& Henry. (2021). Moving Without the Ball in Basketball [Online Article]. Retrieved from https://basketballhq.com/moving-without-ball-basketball; Accessed on 25.1.2021

Fawzy, A. A. (2014). Basketball: History, principles and basic skills. Alexandria, Egypt: World Sports Foundation \& Dar Alwafaa.

Freitas, T. T., Alcaraz, P. E., Bishop, C., Calleja-González, J., Arruda, A. F., Guerriero, A., ... \& Loturco, I. (2019). Change of direction deficit in national team Rugby Union players: is there an Influence of playing position?. Sports, 7(1), 2.

Gambetta, V. (2007). Athletic development. Champaign, IL: Human Kinetics.

Gels, J. (2019). Basketball Fundamentals - Footwork [Online Article]. Retrieved from https://www.coachesclipboard.net/Footwork.html; Accessed on 29.1.2021.

Guide to Coaching Basketball. (2012). How to teach and coach the basic basketball moves without the ball [Online Article]. Retrieved from http://www.guidetocoachingbasketball.com/motion.htm; Accessed on 26.1.2021

Haff, G. G., \& Triplett, N. T. (Eds.). (2016). Essentials of strength training and conditioning 4th edition. Human kinetics.

Hammad, M. I. (2010). Sports Training for Junior and Successful Trainer. Cairo, Egypt: Modern Book House.

Hassanein, M. S. (1987). Evaluate and measurement in physical education. Egypt: Dar Elfikr Elarabi.

Herrán, A., Usabiaga, O., \& Castellano, J. (2017). Comparación del perfil físico entre 3x3 y 5x5 en baloncesto formative [Physical Profile Comparison Between 3x3 and 5x5 Basketball Training]. Revista Internacional de Medicina y Ciencias de la Actividad Física y el Deporte, 17(67), 435- 447. 4 Retrieved http://cdeporte.rediris.es/revista/revista67/artcomparacion831.htm

Izzo, R., \& Lo Castro, L. (2015). The study of acceleration and deceleration capacity decrease in repeated sprints in soccer. International Journal of Physical Education, Sport and Health, 2(2), 2394-1685.

Izzo, R., \& Sopranzetti, S. (2010). Speed, acceleration, deceleration and metabolic power in the work to roles for a workout more targeted in elite football. Med. Sci. Sports Exerc, 42(1), 173.

Johnston, A. (2016, December 2). How to Move without The Ball [Online Article]. Retrieved from https://ballerbootcamp.com/basketball-tutorial-how-to-move-without-the-ball-like-klaythompson/; Accessed on 25.1.2021

Kumar, N. P. (2014). Effect of Basketball Specific Footwork Training Protocol on Selected Offensive and Defensive Skills in Basketball. International Journal of Physical Education, Fitness and Sports, 3(2), 60-67

Loturco, I., A. Pereira, L., T. Freitas, T., E. Alcaraz, P., Zanetti, V., Bishop, C., \& Jeffreys, I. (2019). Maximum acceleration performance of professional soccer players in linear sprints: Is there a direct connection with change-of-direction ability?. PloS one, 14(5), e0216806.

Loturco, I., Nimphius, S., Kobal, R., Bottino, A., Zanetti, V., Pereira, L. A., \& Jeffreys, I. (2018). Change-of direction deficit in elite young soccer players. German Journal of Exercise and Sport Research, 48(2), 228-234. 
Majeed, R. Kh. (1998). Encyclopedia of Measurements and Tests in Physical Education. Iraq, Basra University: Higher Education Press

McGown, R. B., Ball, N. B., Legg, J. S., \& Mara, J. K. (2020). The perceptual, heart rate and technical-tactical characteristics of $3 \times 3$ basketball. International Journal of Sports Science \& Coaching, 15(5-6), 772-782.

Moawad, H. S. (2003). Basketball for all. Cairo, Egypt: Dar Elfikr Elarabi.

Pasanen, K., Ekola, T., Vasankari, T., Kannus, P., Heinonen, A., Kujala, U. M., \& Parkkari, J. (2017). High ankle injury rate in adolescent basketball: A 3-year prospective follow-up study. Scandinavian journal of medicine \& science in sports, 27(6), 643-649.

Pereira, L. A., Nimphius, S., Kobal, R., Kitamura, K., Turisco, L. A., Orsi, R. C., ... \& Loturco, I. (2018). Relationship between change of direction, speed, and power in male and female National Olympic team handball athletes. The Journal of Strength \& Conditioning Research, 32(10), 2987-2994.

Saleh, M. (2019). Sports training strategies for young people. Cairo, Egypt: Modern Book Center.

Sansone, P., Tessitore, A., Lukonaitiene, I., Paulauskas, H., Tschan, H., \& Conte, D. (2020). Technical-tactical profile, perceived exertion, mental demands and enjoyment of different tactical tasks and training regimes in basketball small-sided games. Biology of sport, 37(1), 15.

Sicinski, A. (2008). Basketball Movement Tactics to Outsmart Your Opponent [Online Article]. Retrieved from https://blog.iqmatrix.com/basketball-movement-tactics; Accessed on 26.1.2021

Taskin, M. (2020). Linear and Direction Reverses Sprint Profile with and Without Ball of Young Basketball Players by Positions. International Journal of Applied Exercise Physiology, 9(3), 196-203.

Vázquez-Guerrero, J., Suarez-Arrones, L., Gómez, D. C., \& Rodas, G. (2018). Comparing external total load, acceleration and deceleration outputs in elite basketball players across positions during match play. Kinesiology, 50(2), 228-234.

Young, D., \& Coratella, G. (2021). Acceleration, Deceleration and Dynamic Stress Load in Elite Hurling: A Between-Quarter and Between-Position Comparison. Sports, 9(1), 10.

Zedan, N. M. (2014). Basketball coach guide (1) Physical preparation. Cairo, Egypt: Modern Book House.

Zushi, K. (2006). Effects of plyometrics on the abilities of the jump, footwork and the chest pass in competitive basketball players. Japanese Journal of physical fitness and sports medicine, 55(2), 237-246. 